\title{
25 Research Soure \\ Real-world Treatment and Associated Healthcare \\ Resource Use Among Migraine Patients in Germany
}

Fraence Hardtstock ( $\square$ fraence.hardtstock@ingress-health.com )

Ingress-Health Gmbh

\section{Zaza Katsarava}

Evangelisches Krankenhaus Unna; University of Duiseberg-Essen; Tbilisi Republic of Georgia, Sechenov University

Thomas Wilke

IPAM e V.,

\section{Zeki Kocaata}

Ingress-Health $\mathrm{GmbH}$

Tim Kirchmann

Abbvie Gmbh

Ulf Maywald

AOK PLUS

Alice Eberhardt

Abbvie Gmbh

\section{Research article}

Keywords: Migraine, headache, unmet needs, HCRU, prophylactic medications, triptans

Posted Date: August 14th, 2020

DOI: https://doi.org/10.21203/rs.3.rs-57269/v1

License: (c) (1) This work is licensed under a Creative Commons Attribution 4.0 International License.

Read Full License

Version of Record: A version of this preprint was published at Annals Of Headache Medicine Journal on February 4th, 2021. See the published version at https://doi.org/10.30756/ahmj.2020.04.04. 


\section{Abstract}

\section{Background}

Migraine is still an area of significant unmet therapeutic needs with a high degree of underdiagnosis and undertreatment of patients. This retrospective claims data analysis aimed to describe the acute and prophylactic treatment patterns of German migraine/headache patients as well as associated healthcare resource use $(\mathrm{HCRU})$ and costs.

\section{Methods}

This retrospective, cohort analysis of German claims data from 2013-2017 included over three million publicly insured patients. Continuously insured adult patients were included if they received at least one inpatient or two confirmed outpatient claims for headache or migraine from 2013-2016. Patients were separated into four main cohorts based on their prophylactic/acute prescription ( $\mathrm{Rx}$ ) medication history in 2017. These four groups included patients receiving: neither acute nor prophylactic Rx (cohort $N$ ), only acute $\operatorname{Rx}$ (cohort A), only prophylactic Rx (cohort $P$ ), and both acute and prophylactic Rx (cohort AP). Baseline characteristics were observed from 2013-2016, while treatment and HCRU/costs were assessed in 2017.

\section{Results}

In total, 199,283 patients were included in this analysis (mean age, 49.49 years; $73.04 \%$, female), among which 9,005 prophylactic therapy starters could be identified during $2014-2015$. Overall, $43.47 \%$ of the patients included in the study did not receive acute or prophylactic medication in 2017. Approximately $33.81 \%$ received only acute treatment, while $9.45 \%$ received only prophylactic medication; $13.28 \%$ received both. Only $28.90 \%$ of patients starting a therapy with prophylactic Rx continued this therapy for at least two years. Generally, HCRU and costs were high in the entire study population, with direct costs ranging from $2,288-7,246 €$ per year, and indirect costs due to sick-leave ranging from 868-1,859€.

\section{Conclusions}

Despite experiencing migraine-related hospitalizations and sick-leave, a sizable proportion of patients included in this study only received substantial amounts of acute Rx treatment or no prescribed treatment for migraine whatsoever. Patients who began receiving prophylactic therapy were found to frequently discontinue their therapy early. Thus, there is a high unmet need for the safe, timely, and efficacious use of prophylactic therapies among migraine patients.

\section{Background}

Migraine is one of the most frequently disabling neurological diseases and is the leading cause of disability in adults under the age of 50 [1]. It often manifests in the form of unilateral pain and episodes of pulsating or throbbing headaches with symptoms including nausea and sensitivity to noise/light, as 
well as vomiting [2], [3]. Pharmacological treatment of migraine often includes use of acute therapies, which aim to relieve symptoms during attacks, as well as preventive or prophylactic therapies in order to decrease the severity and frequency of attacks [3], [4]. In addition, several non-pharmacological approaches such as acupuncture and psychotherapy may be considered as treatment options [5], [6].

Due to its diverse symptomology and varying levels of clinical severity, migraine often has a major impact on the quality of patients' lives. In recent years, migraine has been increasingly recognized as one of the most frequent causes of disability [1]. In 2016, migraine was found to be the leading driver of years lived with disability (YLD) worldwide in the age group of 15 to 49 years [7]. Since migraine primarily affects people in their productive years (from a labor market perspective), it leads to substantial productivity losses, and therefore constitutes a serious public-health concern [5], [8], [9].

In addition to these humanistic and social/economic burdens, migraine is also recognized as an area of significant unmet therapeutic need, as it relates to the underdiagnosis and widespread undertreatment of patients [2], [10]. There are a number of reasons for the undertreatment of patients with prophylactic therapies, including the misdiagnosis of many migraine patients with general headache [10]. Ultimately, correct diagnosis and assessment of disease type, as well as the intensity and frequency of attacks, is essential to facilitate appropriate management of migraine [4], [11].

Ultimately, there is very limited evidence on the treatment of migraine patients and associated healthcare resource utilization (HCRU) and costs in Germany. Nevertheless, these data are urgently needed to understand potential avenues for improving the real-world treatment of patients. This retrospective claims data analysis aimed to identify patients with headache and migraine in Germany, and to describe their acute and prophylactic drug treatment as well as HCRU, direct and indirect costs.

\section{Methods}

\section{Study design and data source}

This was a retrospective, non-interventional comparative cohort analysis of patients with migraine or headache, utilizing an anonymized routine dataset provided by AOK PLUS, a German public sickness fund insuring about 3.2 million persons in Germany. Complete statutory insurance data on all documented diagnoses (inpatient and outpatient), treatments and procedures, as well as pharmaceutical and non-pharmaceutical prescriptions for the period 2013-2017 were available. Furthermore, the dataset included information on the cost of prescriptions, hospitalizations, and rehabilitations, as well as outpatient physician visits. As the dataset was anonymized, no ethical approval was required. Approval from the data owner was provided prior to the start of the analysis, based on the submission of a study protocol. The study was led by a Scientific Steering Board, consisting of the authors of this publication.

\section{Patient eligibility criteria}


In order to describe treatment patterns and HCRU in 2017, patients were included if they received at least one inpatient and/or two confirmed outpatient diagnoses of headache (ICD-10 R51 and G44) or migraine (ICD-10 G43) from 2013-2016, and if they were at least 18 years of age and alive on 01/01/2017. Furthermore, patients must have been continuously insured from 2013-2017. Baseline characteristics such as sociodemographic profile, comorbidities, and type of diagnosing physicians (i.e. general practitioners, specialists) were observed from 2013-2016 in four main patient cohorts.

\section{Analysis of treatment patterns}

Both acute and prophylactic prescriptions (Rx) were analyzed in the observational year 2017 to group patients based on their medication therapy. Data on over the counter (OTC) drugs were not available. The study considered a range of acute medications including triptans, analgesics, antiemetics and ergot alkaloids, as well as prophylactic agents which included propranolol, metoprolol, bisoprolol, flunarizine, topiramate, amitriptyline, onabotulinumtoxinA, and valproic acid. A list of all observed agents and their respective anatomical therapeutic chemical (ATC) codes is presented in Appendix Table 1. Patients were assigned to one of four main cohorts, based on the type of Rx treatment they received in 2017, including: neither acute nor prophylactic medication (cohort $N$ ), only acute medication (cohort $A$ ), only prophylactic medication (cohort P), or both acute and prophylactic medication (cohort AP) (Fig. 1).

The number of prescriptions and average dosage received was calculated per agent as well as per drug class and reported for the four treatment cohorts. A proxy for prescribed daily dosage was calculated based on available information about package size and defined daily doses (DDD) for medications according to the World Health Organization (WHO) [12].

In a separate analysis, migraine/headache patients who began receiving prophylactic treatment in 20142015 were observed in order to identify treatment lines, switches, and treatment discontinuation in the period following initiation of treatment. Patients who began receiving prophylactic treatment (including at least one of the above prophylactic agents) between 01/01/2014-31/12/2015 and had no prophylactic treatment history in 2013 were included in the analysis. The first prescription for prophylactic treatment was considered as the index date and all patients were observed for 24 months after initiation of therapy. Discontinuation of therapy was considered, when a patient did not refill a prescription for his/her prophylactic medication within 180 days of the last expected drug coverage date of the last observed prescription.

In addition, an exploratory analysis was performed to estimate the number of patients with migraine/headache who did not receive prophylactic medication in 2016 but may have benefited from such a therapy. A potential need for a prophylactic medication was defined as having received $>8$ DDDs triptans per month in 2016, or alternatively > 5 DDDs triptans per month in combination with either (i) an emergency room (ER) visit with a diagnosis of headache/migraine, (ii) at least one migraine/headacheassociated hospitalization, or (iii) an inpatient rehabilitation stay associated with headache/migraine in 2016. For all patients with an identified need for prophylactic therapy in 2016, prescriptions of prophylactic medications were observed in 2017. 


\section{Analysis of HCRU and cost}

The following HCRU variables were observed and reported per patient-year (ppy): inpatient hospitalizations, outpatient physician visits, inpatient rehabilitation stays, physiotherapy prescriptions, prescribed aids and remedies, acupuncture prescriptions, and days absent from work. Overall costs $(€)$ were reported ppy for the following categories: (i) outpatient visits [based on documented 'treatment points' for outpatient physician visits], (ii) outpatient prescriptions [based on official retail list prices for outpatient medication prescriptions], (iii) hospitalizations, including procedures and medications [based on diagnosis-related group reimbursements for inpatient hospitalizations], (iv) inpatient rehabilitations [directly covered in the database], and (v) prescriptions of aids and remedies [based on prices, which are directly covered in the database]. Since patient-specific salaries were not available in the database, indirect costs related to loss of productivity were approximated based on the number of days absent from work, multiplied by age- and gender-specific average gross salaries in Germany [13]. HCRU and cost analyses were repeated for the exploratory cohort of patients who did not receive prophylactic treatment in 2016, but may have benefited from it (i.e. those receiving $>8$ DDDs triptans per month or $>5$ DDDs in combination with further criteria as previously described).

\section{Results}

\section{Patient characteristics}

We identified 199,283 patients with headache and/or migraine in our database (mean age 49.49 years; $73.04 \%$ women; Table 1). Among patients included in the study, $6.46 \%$ did not receive an outpatient diagnosis of migraine or headache, but were diagnosed with headache/migraine at least once during an inpatient stay, while $93.54 \%$ of the patients were diagnosed in an outpatient setting (55.63\% with migraine diagnoses and $37.91 \%$ with headaches but not migraine).

Most observed comorbidities in the identified headache/migraine patients included back pain (73.35\%), abdominal and pelvic pain (44.49\%), arthrosis (32.08\%) and depression (31.88\%). Patients without any prescription of acute or prophylactic medication (cohort $\mathrm{N}$ ) were younger (mean age 42.83 vs. $48.42-$ 63.85), less often female (69.72\% vs. $73.93 \%-78.12 \%$ ), and with less severe comorbidities (mean $\mathrm{CCl} 1.06$ vs. 1.59-3.43) than patients receiving acute medication (cohort $A$ ), prophylactic medication (cohort $P$ ) and/or acute and prophylactic medication (cohort AP). 
Table 1

Baseline characteristics of observed patients, measured from 2013-2016

\begin{tabular}{|c|c|c|c|c|c|}
\hline & $\begin{array}{l}\text { All } \\
\text { patients }\end{array}$ & Cohort N & Cohort A & Cohort P & $\begin{array}{l}\text { Cohort } \\
\text { AP }\end{array}$ \\
\hline $\mathrm{N}$ & 199,283 & 86,625 & 67,375 & 18,825 & 26,458 \\
\hline \multirow[t]{2}{*}{$\%$ of all patients } & - & 43.47 & 33.81 & 9.45 & 13.28 \\
\hline & \multicolumn{5}{|c|}{ Sociodemographic characteristics } \\
\hline Age; Mean (SD) / Median & $\begin{array}{l}49.49 \\
(19.52) / \\
50\end{array}$ & $\begin{array}{l}42.83 \\
(17.97) / \\
39\end{array}$ & $\begin{array}{l}48.42 \\
(18.60) / \\
49\end{array}$ & $\begin{array}{l}63.71 \\
(15.87) / \\
65\end{array}$ & $\begin{array}{l}63.85 \\
(15.93) / \\
64\end{array}$ \\
\hline Females; N (\%) & $\begin{array}{l}145,549 \\
(73.04)\end{array}$ & $\begin{array}{l}60,398 \\
(69.72)\end{array}$ & $\begin{array}{l}50,566 \\
(75.05)\end{array}$ & $\begin{array}{l}13,917 \\
(73.93)\end{array}$ & $\begin{array}{l}20,668 \\
(78.12)\end{array}$ \\
\hline \multirow{2}{*}{$\begin{array}{l}\text { Pregnant women; } \mathrm{N} \text { (\% of females } \\
\text { with at least one pregnancy) }\end{array}$} & \multirow{2}{*}{$\begin{array}{l}13,941 \\
(9.58)\end{array}$} & \multirow{2}{*}{$\begin{array}{l}8,610 \\
(14.26)\end{array}$} & 4,713 & 259 & 359 \\
\hline & & & $(9.32)$ & $(1.86)$ & (1.74) \\
\hline & \multicolumn{5}{|c|}{ Migraine/headache diagnosis } \\
\hline Migraine diagnosis by... & 55.63 & 54.52 & 58.89 & 51.11 & 51.14 \\
\hline General practitioner only; \% & 35.03 & 35.58 & 36.35 & 33.61 & 30.86 \\
\hline any specialist; \% & 20.60 & 18.93 & 22.54 & 17.50 & 23.28 \\
\hline a neurologist (subgroup); \% & 7.63 & 5.45 & 8.75 & 7.09 & 12.28 \\
\hline Headache diagnosis by... & 37.91 & 40.49 & 35.65 & 37.90 & 35.26 \\
\hline \multicolumn{6}{|l|}{ [patients without migraine $\mathrm{dx}$ ] } \\
\hline General practitioner only; \% & 19.84 & 23.06 & 18.27 & 17.33 & 15.08 \\
\hline any specialist; \% & 18.08 & 17.43 & 17.38 & 20.56 & 20.18 \\
\hline \multirow[t]{2}{*}{ a neurologist (subgroup); \% } & 4.98 & 3.86 & 4.70 & 7.41 & 7.65 \\
\hline & \multicolumn{5}{|c|}{ Comorbidities } \\
\hline CCl; Mean (SD) / Median & $\begin{array}{l}1.74 \\
(2.47) / \\
1.00\end{array}$ & $\begin{array}{l}1.06 \\
(1.80) \\
10.00\end{array}$ & $\begin{array}{l}1.59 \\
(2.28) \\
/ 1.00\end{array}$ & $\begin{array}{l}3.00 \\
(2.47) \\
/ 2.00\end{array}$ & $\begin{array}{l}3.43 \\
(3.19) \\
/ 3.00\end{array}$ \\
\hline \multirow{2}{*}{\multicolumn{6}{|c|}{$\begin{array}{l}\text { Patients with diagnosis } \\
\text { (ICD-10 codes) of... }\end{array}$}} \\
\hline & & & & & \\
\hline Back pain/Dorsalgia (M54); \% & 73.35 & 65.88 & 78.63 & 73.53 & 84.23 \\
\hline Abdominal and pelvic pain (R10); \% & 44.49 & 43.53 & 48.03 & 36.19 & 44.50 \\
\hline Arthrosis (M15-M19); \% & 32.08 & 19.44 & 33.91 & 46.00 & 58.92 \\
\hline
\end{tabular}




\begin{tabular}{|llllll|}
\hline & $\begin{array}{l}\text { All } \\
\text { patients }\end{array}$ & Cohort N & Cohort A & Cohort P & $\begin{array}{l}\text { Cohort } \\
\text { AP }\end{array}$ \\
\hline Depressive episode (F32); \% & 31.88 & 25.68 & 33.60 & 36.58 & 44.46 \\
\hline Other joint disorder (M25); \% & 28.14 & 22.56 & 31.85 & 27.29 & 37.57 \\
\hline Spondylopathies (M45-M49); \% & 27.33 & 17.30 & 29.68 & 35.50 & 48.35 \\
\hline $\begin{array}{l}\text { Other soft tissue disorders, not } \\
\text { elsewhere classified (M79); \% }\end{array}$ & 24.86 & 19.92 & 28.15 & 24.57 & 32.86 \\
\hline $\begin{array}{l}\text { Other anxiety disorders (F41); \% } \\
\text { Pain, unspecified (R52); \% }\end{array}$ & 21.12 & 18.07 & 21.57 & 24.21 & 27.76 \\
\hline $\begin{array}{l}\text { Pain assoc. with fem. genital organs } \\
\text { and menstrual cycle (N94); \% }\end{array}$ & 19.55 & 23.59 & 21.53 & 8.36 & 9.27 \\
\hline
\end{tabular}

\section{Treatment patterns}

\section{Cross-sectional analysis 2017}

Overall, $43.47 \%$ of all observed patients $(86,625 / 199,283)$ did not receive prescriptions for acute or prophylactic medication in 2017 (cohort N). In 67,375 (33.81\%) of all observed patients, only prescription of acute medications was observed (cohort $\mathrm{A}$ ), with $12.53 \%$ receiving triptans. Patients who only received prophylactic medication and no acute medication accounted for $9.45 \%$ of the observed cohort $(18,825 / 199,283$; cohort $P)$, among which most received either metoprolol (43.89\%) or bisoprolol $(45.68 \%)$. All remaining patients $(13.28 \% ; 26,458 / 199,283)$ received both acute and prophylactic therapy (cohort AP), among which $12.69 \%$ received triptans (Table 2 ).

In addition to pharmacological treatment of migraine, other forms of non-pharmacological treatment were also analyzed. The number of patients receiving opioids varied among each group, ranging from $2.94 \%$ in cohort $\mathrm{N}$ to $24.57 \%$ in cohort AP. Only a small proportion of patients in the study received a prescription for acupuncture (1.29\%) or for physiotherapy (6.59\%). In cohorts receiving acute treatment for migraine (cohorts A and AP), a higher percentage of patients was found to receive nonpharmacological therapies (as compared to patients in cohorts $\mathrm{N}$ and $\mathrm{P}$ ) (Table 2). 
Table 2

Pharmacological and non-pharmacological treatment of patients in 2017

\begin{tabular}{|c|c|c|c|c|c|}
\hline & $\begin{array}{l}\text { All } \\
\text { patients }\end{array}$ & Cohort N & Cohort A & Cohort P & $\begin{array}{l}\text { Cohort } \\
\text { AP }\end{array}$ \\
\hline \multirow[t]{2}{*}{$\mathrm{N}$} & 199,283 & 86,625 & 67,375 & 18,825 & 26,458 \\
\hline & & $(43.47 \%)$ & $(33.81 \%)$ & $(9.45 \%)$ & $(13.28 \%)$ \\
\hline & \multicolumn{5}{|c|}{ Pharmacological treatment 2017} \\
\hline $\begin{array}{l}\text { Patients with acute medications; } \\
\text { total }\end{array}$ & $47.09 \%$ & $0.00 \%$ & $100.00 \%$ & $0.00 \%$ & $100.00 \%$ \\
\hline triptans & $5.92 \%$ & - & $12.53 \%$ & - & $12.69 \%$ \\
\hline analgesics & $43.28 \%$ & - & $91.61 \%$ & - & $92.73 \%$ \\
\hline antiemetics & $3.72 \%$ & - & $7.27 \%$ & - & $9.52 \%$ \\
\hline ergot alkaloids & $0.02 \%$ & - & $0.03 \%$ & - & $0.05 \%$ \\
\hline \multicolumn{5}{|l|}{ prophylactic medications; total } & $100.00 \%$ \\
\hline propranolol & $0.72 \%$ & - & - & $3.21 \%$ & $3.16 \%$ \\
\hline metoprolol & $9.86 \%$ & - & - & $43.89 \%$ & $43.06 \%$ \\
\hline bisoprolol & $9.97 \%$ & - & - & $45.68 \%$ & $42.55 \%$ \\
\hline flunarizine & $0.08 \%$ & - & - & $0.19 \%$ & $0.49 \%$ \\
\hline topiramate & $0.71 \%$ & - & - & $1.74 \%$ & $4.08 \%$ \\
\hline amitriptyline & $2.11 \%$ & - & - & $6.25 \%$ & $11.41 \%$ \\
\hline onabotulinumtoxinA & $0.18 \%$ & - & - & $0.67 \%$ & $0.87 \%$ \\
\hline valproic acid & $0.70 \%$ & - & - & $3.22 \%$ & $2.95 \%$ \\
\hline \multirow[t]{2}{*}{ Patients with opioids; total } & $9.55 \%$ & $2.94 \%$ & $12.08 \%$ & $9.75 \%$ & $24.57 \%$ \\
\hline & \multicolumn{5}{|c|}{ Non-pharmacological treatment 2017} \\
\hline Patients with acupuncture & $1.29 \%$ & $0.63 \%$ & $1.66 \%$ & $1.30 \%$ & $2.52 \%$ \\
\hline \multicolumn{6}{|l|}{ Patients with prescriptions of... } \\
\hline physiotherapy & $6.59 \%$ & $2.78 \%$ & $8.73 \%$ & $6.54 \%$ & $13.66 \%$ \\
\hline manual therapy & $9.52 \%$ & $5.34 \%$ & $13.27 \%$ & $7.60 \%$ & $15.07 \%$ \\
\hline classic massage therapy & $1.55 \%$ & $0.79 \%$ & $1.85 \%$ & $1.74 \%$ & $3.16 \%$ \\
\hline
\end{tabular}




\begin{tabular}{|llllll|}
\hline & $\begin{array}{l}\text { All } \\
\text { patients }\end{array}$ & Cohort N & Cohort A & Cohort P & $\begin{array}{l}\text { Cohort } \\
\text { AP }\end{array}$ \\
\hline warm/cold therapy & $0.61 \%$ & $0.26 \%$ & $0.89 \%$ & $0.58 \%$ & $1.08 \%$ \\
\hline Longitudinal analysis of prophylactic therapy starters & & & & \\
\hline
\end{tabular}

For the longitudinal analysis, 9,005 patients who began receiving prophylactic treatment in 2014-2015, were identified in the database. Their mean age at initiation of therapy was 52.19 years, and $78.48 \%$ of observed patients were women. Most of these patients started therapy with bisoprolol (33.97\%), followed by metoprolol (31.17\%) and amitriptyline $(21.11 \%)$. Other prophylactic agents used in treatment included topiramate (5.97\%), propranolol (3.75\%), valproic acid (1.19\%), flunarizine $(0.73 \%)$, onabotulinumtoxinA $(0.48 \%)$ or any combination of the agents mentioned above $(1.62 \%)$.

Among this group, 5,726 patients (63.59\%) received at least one prescription for acute medication in the 12 months prior to initiation of prophylactic therapy. Of those, 1,399 patients received triptans. For the latter, on average, triptans were available for 4.71 days per month. In contrast, during the first 12 months after initiation of prophylactic therapy, 5,698 patients $(63.28 \%)$ received acute medications. Here, 1,432 patients received at least one prescription of triptans, with 4.85 days per month of available triptans (Fig. 2).

Overall, 2,602 patients (28.89\%) continued their first-line prophylactic therapy for at least two years following initiation, while 930 patients $(10.33 \%)$ switched to another second-line prophylactic therapy, and 5,473 patients $(60.78 \%)$ discontinued their first-line therapy without starting a new prophylactic therapy. Time until discontinuation for the last group of patients was on average 112 days.

\section{Exploratory analysis of patient's needs for prophylactic medication}

Among all 199,283 observed patients, 154,131 (77.34\%) did not receive a prescription for prophylactic medication in 2016. In the same year, 948 of those patients received > 8 DDDs triptans per month, while an additional 32 patients received $>5$ DDDs triptans and experienced at least one migraine/headacheassociated ER visit, hospitalization or inpatient rehabilitation stay. Among these 980 patients, a minority of 115 patients (11.7\%) received a prophylactic medication in 2017.

\section{HCRU and costs in 2017}

\section{HCRU}

For nearly all observed HCRU/cost variables, a higher utilization was found in patients receiving prophylactic treatment (cohorts AP and P), compared to patients without medication (cohort N) or with only acute Rx (cohort A). HCRU and cost were also reported for the exploratory cohort of 980 patients expected to benefit from prophylactic treatment (those who received substantial monthly doses of triptans, but no prophylactic Rx). In these patients, migraine/headache related HCRU was comparatively high. 
On average patients in cohort AP were hospitalized (for any cause) around 0.90 times per year, a rate which is over three-fold higher than that which was observed in patients from cohort $\mathrm{N}$ who received no treatment $(0.28 \mathrm{ppy})$. Furthermore, migraine/headache-related hospitalizations were $0.06 \mathrm{ppy}$ in cohort AP as compared to 0.01 ppy in cohort N. In the cohort of 980 patients with no prophylactic treatment but high triptan use, the rate of migraine/headache-related hospitalizations was 0.05 ppy.

The number of patients with sick leave and the number of days of sick leave were both higher in patients from cohort A, in comparison to patients who received a prophylactic medication (cohorts AP and P). Patients in cohort $A$ took on average 17.04 days of sick leave (1.06 days related to migraine and/or headache), compared to an average of 7.52 days (0.54 days) in patients from cohort $P$, and 11.77 days (1.25 days) in patients from cohort AP. For the exploratory cohort of 980 patients, the number of patients who had at least one absence (51.22\%) was higher than in all other cohorts (21.59\%-47.76\%).

Furthermore, for this cohort, the number of days of missed work due to migraine/headache was 3.94 days ppy, and therefore significantly higher than in all other cohorts (0.43-0.54 days ppy). 


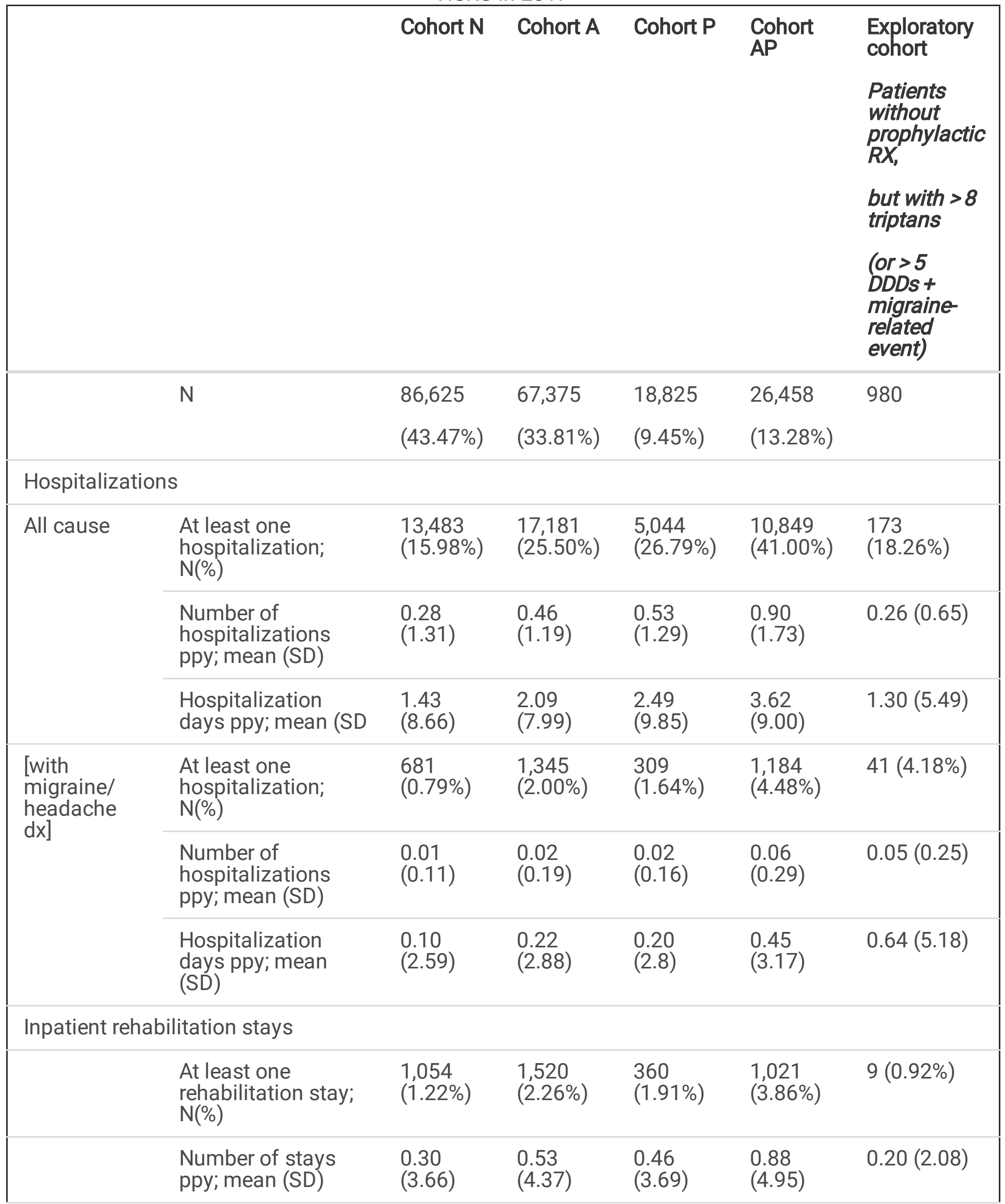


Outpatient visits with

migraine/headache diagnosis

\begin{tabular}{|c|c|c|c|c|c|c|}
\hline \multirow[t]{2}{*}{$\begin{array}{l}\text { General } \\
\text { practitioner }\end{array}$} & $\begin{array}{l}\text { At least one visit; } \\
\mathrm{N}(\%)\end{array}$ & $\begin{array}{l}76,794 \\
(88.65 \%)\end{array}$ & $\begin{array}{l}65,691 \\
(97.50 \%)\end{array}$ & $\begin{array}{l}18,538 \\
(98.48 \%)\end{array}$ & $\begin{array}{l}26,096 \\
(98.63 \%)\end{array}$ & $\begin{array}{l}955 \\
(97.45 \%)\end{array}$ \\
\hline & $\begin{array}{l}\text { Number of visits } \\
\text { ppy; mean (SD) }\end{array}$ & $\begin{array}{l}2.92 \\
(1.96)\end{array}$ & $\begin{array}{l}3.91 \\
(1.93)\end{array}$ & $\begin{array}{l}4.31 \\
(1.72)\end{array}$ & $\begin{array}{l}4.70 \\
(1.99)\end{array}$ & $4.37(2.02)$ \\
\hline \multirow{2}{*}{$\begin{array}{l}\text { General } \\
\text { practitioner } \\
\text { [with } \\
\text { migraine/ } \\
\text { headache } \\
\text { dx] }\end{array}$} & $\begin{array}{l}\text { At least one visit; } \\
\mathrm{N}(\%)\end{array}$ & $\begin{array}{l}32,476 \\
(37.49 \%)\end{array}$ & $\begin{array}{l}34,283 \\
(50.88 \%)\end{array}$ & $\begin{array}{l}8,444 \\
(44.86 \%)\end{array}$ & $\begin{array}{l}13,209 \\
(49.92 \%)\end{array}$ & $\begin{array}{l}913 \\
(93.16 \%)\end{array}$ \\
\hline & $\begin{array}{l}\text { Number of visits } \\
\text { ppy; mean (SD) }\end{array}$ & $\begin{array}{l}0.98 \\
(1.56)\end{array}$ & $\begin{array}{l}1.57 \\
(1.92)\end{array}$ & $\begin{array}{l}1.58 \\
(1.98)\end{array}$ & $\begin{array}{l}1.83 \\
(2.15)\end{array}$ & $3.92(2.00)$ \\
\hline \multirow[t]{2}{*}{ Neurologist } & $\begin{array}{l}\text { At least one visit; } \\
\mathrm{N}(\%)\end{array}$ & $\begin{array}{l}7,950 \\
(9.18 \%)\end{array}$ & $\begin{array}{l}11,362 \\
(16.86 \%)\end{array}$ & $\begin{array}{l}4,205 \\
(22.34 \%)\end{array}$ & $\begin{array}{l}8,095 \\
(30.60 \%)\end{array}$ & $\begin{array}{l}266 \\
(27.14 \%)\end{array}$ \\
\hline & $\begin{array}{l}\text { Number of visits } \\
\text { ppy; mean (SD) }\end{array}$ & $\begin{array}{l}0.22 \\
(0.80)\end{array}$ & $\begin{array}{l}0.41 \\
(1.06)\end{array}$ & $\begin{array}{l}0.63 \\
(1.33)\end{array}$ & $\begin{array}{l}0.86 \\
(1.49)\end{array}$ & $0.76(1.42)$ \\
\hline \multirow{2}{*}{$\begin{array}{l}\text { Neurologist } \\
\text { [with } \\
\text { migraine/ } \\
\text { headache } \\
\text { dx] }\end{array}$} & $\begin{array}{l}\text { At least one visit; } \\
\mathrm{N}(\%)\end{array}$ & $\begin{array}{l}2,608 \\
(3.01 \%)\end{array}$ & $\begin{array}{l}4,712 \\
(6.99 \%)\end{array}$ & $\begin{array}{l}1,554 \\
(8.25 \%)\end{array}$ & $\begin{array}{l}3,768 \\
(14.24 \%)\end{array}$ & $\begin{array}{l}223 \\
(22.76 \%)\end{array}$ \\
\hline & $\begin{array}{l}\text { Number of visits } \\
\text { ppy; mean (SD) }\end{array}$ & $\begin{array}{l}0.08 \\
(0.52)\end{array}$ & $\begin{array}{l}0.19 \\
(0.83)\end{array}$ & $\begin{array}{l}0.25 \\
(0.96)\end{array}$ & $\begin{array}{l}0.46 \\
(1.33)\end{array}$ & $0.78(1.71)$ \\
\hline \multicolumn{7}{|l|}{ Sick days } \\
\hline \multirow[t]{2}{*}{ All-cause } & $\begin{array}{l}\text { At least one } \\
\text { absence; } \mathrm{N}(\%)\end{array}$ & $\begin{array}{l}36,792 \\
(42.47 \%)\end{array}$ & $\begin{array}{l}32,177 \\
(47.76 \%)\end{array}$ & $\begin{array}{l}4,065 \\
(21.59 \%)\end{array}$ & $\begin{array}{l}6,523 \\
(24.65 \%)\end{array}$ & $\begin{array}{l}502 \\
(51.22 \%)\end{array}$ \\
\hline & $\begin{array}{l}\text { Number of days } \\
\text { absent; mean (SD) }\end{array}$ & $\begin{array}{l}9.79 \\
(25.47)\end{array}$ & $\begin{array}{l}17.04 \\
(37.04)\end{array}$ & $\begin{array}{l}7.52 \\
(28.24)\end{array}$ & $\begin{array}{l}11.77 \\
(36.14)\end{array}$ & $\begin{array}{l}18.63 \\
(41.17)\end{array}$ \\
\hline \multirow{2}{*}{$\begin{array}{l}\text { [with } \\
\text { migraine/ } \\
\text { headache } \\
d x \text { ] }\end{array}$} & $\begin{array}{l}\text { At least one } \\
\text { absence; } \mathrm{N}(\%)\end{array}$ & $\begin{array}{l}3,475 \\
(4.01 \%)\end{array}$ & $\begin{array}{l}4,806 \\
(7.13 \%)\end{array}$ & $\begin{array}{l}390 \\
(2.07 \%)\end{array}$ & $\begin{array}{l}1,192 \\
(4.51 \%)\end{array}$ & 168 (17.14) \\
\hline & $\begin{array}{l}\text { Number of days } \\
\text { absent; mean (SD) }\end{array}$ & $\begin{array}{l}0.43 \\
(5.77)\end{array}$ & $\begin{array}{l}1.06 \\
(10.59)\end{array}$ & $\begin{array}{l}0.54 \\
(8.92)\end{array}$ & $\begin{array}{l}1.25 \\
(13.14)\end{array}$ & $3.49(20.58)$ \\
\hline
\end{tabular}

\section{Cost}

Total (all cause) direct costs ppy ranged from $2,288.14 €$ in cohort $N$ to $7,246.18 €$ in cohort AP, as indicated in Fig. 3. Hospitalizations accounted the largest share of costs in all cohorts $(38.81 \%-46.24 \%$ of total direct costs), except for in the explanatory cohort (22.69\%), where outpatient visits and prescriptions accounted for a higher proportion of total direct costs. Rehabilitation stays had the lowest impact on overall direct costs comprising only $0.86 \%-2.22 \%$. On average, patients in Cohort AP incurred the highest direct costs across all categories, while patients in cohort $\mathrm{N}$ incurred the lowest. Indirect costs associated with loss of productivity due to days absent from work were lowest in cohort P (868.19€ ppy) and 
highest in cohort A $(1,861.24 €$ ppy); patients in the exploratory cohort incurred an indirect cost of $2,031.73 €$ ppy.

\section{Discussion}

\section{Summary and comparison of findings with existing literature}

In this study, we analyzed patients with headache/migraine in a real-world setting in order to increase knowledge related to current treatment patterns of these patients in Germany. The goal of this research is to outline ongoing challenges related to the diagnosis and treatment of migraine patients in order to pave the way for improvements in medical care for patients with migraine.

Management of migraine and headache is multidimensional. Emphasis should be placed upon educating patients about appropriate use of OTC medication, improving the quality of advice provided to patients by pharmacists, as well as integrating, coordinating and synchronizing services offered by primary healthcare providers as well as specialists. Around $50 \%$ of migraine patients with relatively mild and infrequent attacks attempt to independently manage their disease through use of OTC remedies, and thus may not consult a physician. Nevertheless, at least $50 \%$ of patients require some degree of medical follow-up or consultation [14]. To a large extent, demand for clinical consultations among migraine patients is driven by the inefficacy of OTC drugs and the resulting need for prescription treatment. It has been previously reported that up to one-third of all migraine patients who suffer from frequent migraine attacks, are probably in need of prophylactic medication [4]. It is particularly important for these patients to receive adequate treatment to improve clinical outcomes, well-being, and productivity in the workplace [15], [16]. Our findings indicate that, even in a relatively well-resourced country like Germany, only a small portion of patients expected to benefit from migraine medication actually receive treatment.

Our study reveals that nearly half of all patients with migraine/headache diagnoses did not receive any prescription of acute or prophylactic medication in 2017 (43.47\%). Approximately one-third of the patients received only acute medications (33.81\%) and just one fifth $(22.72 \%)$ were prescribed prophylactic agents. Our exploratory analysis of patients who heavily depend on prescribed triptans (> 8DDDs per months or $>5$ DDDs per months with additional indicators of high disease severity) revealed a stark unmet need for prophylactic agents, since less than $10 \%$ of these patients received subsequent prescriptions for prophylactic medication. These findings align with those of previous studies which have demonstrated generally poor treatment patterns and disease performance in headache/migraine patients throughout Germany and elsewhere in Europe. A recent medical chart review reported that $27.5 \%-58.4 \%$ of migraine patients do not receive any therapy [17], while a study of 8,000 migraine patients from $10 \mathrm{EU}$ countries confirmed that very few patients received adequate migraine-specific treatment including both, acute and prophylactic medications [8]. Further to these findings, one study in Germany demonstrated an 
overall low frequency of migraine-specific prescriptions, especially among general practitioners (GPs) [17].

However, reasons for the low quality of care afforded to migraine and headache in patients throughout Germany and across the world are manifold. Despite the fact that migraine is highly prevalent and is associated with huge adverse consequences for affected people and the society, it is generally not considered a significant medical problem by patients, healthcare providers and health policymakers [18]. Oftentimes people affected by migraine are not aware of their disease and thus, do not consult a doctor to receive a diagnosis or proper treatment for their symptoms. One study provided evidence that awareness of migraine was low among both affected patients and healthcare providers [19]. These findings were corroborated by a study in France which indicated that $60 \%$ of 10,000 patients with migraine were unaware of their diagnosis [20]. With this in mind, we acknowledge potential underestimation of unmet need in our patient population, since not all patients in need of therapy will have visited physicians during the study period and, therefore, were not included in this analysis. A previous study in Germany provided evidence that only $42 \%$ of patients with migraine consulted a physician, while a clear majority of patients relied exclusively on OTC medications, despite reporting symptoms [21]. This presents a limitation of the present study, as data on OTC medication use for our patient population were not available in the dataset.

In addition to the potential lack of awareness regarding migraine diagnoses, some GPs and specialists may not perceive headaches to be medically important enough to spend time diagnosing/treating symptoms, providing patients with detailed advice, or following-up with regard to the presentation of new symptoms. A study conducted in 10 headache centers in Italy revealed that only $26.8 \%$ of patients with migraine had received a previous diagnosis that was correct [22]. Another multinational study found that only 28 percent of migraine patients (who were subsequently referred to specialized headache centers) had been diagnosed with migraine by their treating GPs [23]. Furthermore, as shown by a study conducted in the UK, some GPs do not follow established treatment guidelines when patients with headache symptoms attend their practice [24]. As a consequence, patients receive either no treatment or improper treatment, as demonstrated in the Europe-wide EUROLIGHT study [8].

However, among patients who received a new prescription for prophylactic therapy in our study $(\mathrm{N}=$ $9,005), 60.78 \%$ discontinued prophylactic treatment within two years, without re-initiation. Ultimately, low medication compliance constitutes another key driver of poor medical care and high unmet need among patients. Poor adherence to prophylactic medication for migraine has been observed in previous research and was shown to result from insufficient effectiveness and/or treatment-related side effects [25]. One retrospective claims analysis in the US revealed that over two-thirds of chronic migraine patients discontinued their medication within six months of initiation, and that more than $80 \%$ of patients discontinued treatment within twelve months [26]. Such challenges related to treatment adherence and potential side effects signal an ongoing need for the improvement of migraine therapies, with regard to effectiveness and safety. 
Our HCRU and cost analysis confirmed high levels of unmet need in a substantial proportion of observed patients, particularly in those who receive medications. According to our analysis, patients taking prophylactic medications were hospitalized more frequently and logged more sick days than patients who did not receive prophylactic treatment. Although this may be due in part to the likelihood of more severe cases among those who received prophylactic treatment, and these findings are likely biased by indication (i.e. higher proportion of migraine patients in this cohort), patients with prophylactic migraine medications had higher utilization of acute medications too, indicating a higher headache frequency. Unfortunately, no data on headache frequency among study participants was available in the database to confirm this. Generally, economic consequences of migraine, comprised of direct and indirect costs, are enormous.

Cost estimates are an important measure used to inform health policymaking via the estimation of expenses incurred by different healthcare services. In Europe, financial costs attributed to migraine are estimated to range between $50 €$ and $111 €$ billion, with direct and indirect costs accounting for $7 \%$ and $93 \%$ respectively [27]. Direct costs incurred by healthcare services attributed to migraine, were found to be $1,222 €$ per person [27]. Another European study reported comparable average costs over three months, ranging from $373.8 €$ in Germany to $929.6 €$ in the UK [28]. Indirect costs, as shown within these studies, constitute most of the economic burden, with productivity loss accounting for two-thirds of indirect costs [27]. Our analysis confirmed that indirect costs (related to days absent from work) should not be neglected in analyses of migraine related HCRU and cost. On the contrary, it must be emphasized that average monthly costs associated with diminished productivity at work (presenteeism) are higher than those arising from sick leave (absenteeism) [29]. However, an estimation of costs related to onsite productivity loss was not possible in this study and research in this area is generally limited.

\section{Limitations}

Strengths of this study include an absence of study site/patient selection bias, coverage of all inpatient and outpatient healthcare sectors, and utilization of a large cohort of 199,283 patients. Nevertheless, we acknowledge that some limitations may apply. First, generalizability of results could be affected by the fact that the health insurance fund which provided the data only covers patients in two regions of Germany (Saxony and Thuringia). However, since health reimbursement rules are identical across Germany, considerable differences in the management of migraine patients are not expected. Second, information on the number of migraine attacks in observed patient cohorts was not available. Third, analysis of prophylactic treatment with monoclonal antibodies such as erenumab, galcanezumab and fremanezumab was not included as these medications were not available during the period of observation. Fourth, dosage as well as persistence analyses were conducted using data on filled prescriptions only. Information on unfilled prescriptions as well as OTC medications was not analyzed, as those data were not available in the relevant sickness fund dataset. Ultimately, the latter may have caused an underestimation of medication use in our patient population. Moreover, HCRU among headache/migraine patients may have been underestimated if alternate therapies not covered by the

Page 15/23 
participating sickness fund were accessed by patients via alternate means (i.e. supplementary insurance, out-of-pocket payments, etc.). Fifth, this analysis was exclusively descriptive, and no adjusted analyses were performed. Finally, our HCRU and cost analysis was based on reimbursements only, which exclude patient co-payments. However, these costs are generally low in Germany.

\section{Conclusions}

Can the introduction of effective medical services for migraine improve clinical outcomes and costsaving measures? The benefits are potentially enormous, both in terms of enhancing economic outcomes as well as addressing unmet needs in one billion people who are affected globally. As presented in this paper there are multiple key elements for improving the medical care of headache and migraine patients in Germany. Firstly, patients must receive better education about the disease and available treatment options, including the effective use of OTC drugs. This education could potentially be provided by public health-education programs. In addition, there is an ongoing need for healthcare providers (and especially GPs), to increase their respective knowledge of how to recognize, diagnose, and properly treat migraine. As such, physicians should inform themselves of and consistently adhere to recommended clinical guidelines, while educating patients on the importance of treatment adherence. Furthermore, healthcare services for patients with headache and migraine should be provided nationally in a structured, effective, and equitable manner. Finally, the development of new therapeutic options with increased effectiveness and tolerability, if adequately applied by physicians, offers targeted patients with a critical opportunity to relieve their symptoms and address ongoing challenges associated with persistent migraine.

\section{Abbreviations}




\begin{tabular}{|ll|}
\hline Abbreviation & Definition of abbreviated term \\
\hline 1L & First line \\
\hline ATC & Anatomical Therapeutic Chemical \\
\hline DDD & Defined Daily Doses \\
\hline Dx & Diagnosis \\
\hline ER & Emergency Room \\
\hline GP & General Practitioner \\
\hline HCRU & Healthcare Resource Utilization \\
\hline ICD-10 & $\begin{array}{l}\text { International Statistical Classification of Diseases and Related Health Problems, 10 } \\
\text { revision }\end{array}$ \\
\hline OTC & Over the counter \\
\hline PPY & Per patient-year \\
\hline Rx & Prescription \\
\hline WHO & World Health Organization \\
\hline YLD & Years Lived with Disability \\
\hline
\end{tabular}

\section{Declarations}

\section{Ethics approval and consent to participate}

Due to the non-interventional, retrospective nature of this study and because our analysis involved an anonymized dataset, neither ethical review nor informed consent of the patients was required. However, the study protocol was reviewed and approved by the sickness fund (AOK PLUS), before access to the data was granted.

\section{Consent for publication}

Non-applicable

\section{Availability of data and materials}

The data that support the findings of this study are abstracted from individual patient records. Data were available for research purposes from the sickness fund upon request, in an anonymized form. Due to 
restrictions around revealing patients' confidential information, data were used under license for the current study, and so are neither publicly available nor can be shared further.

\section{Competing interests}

Alice Eberhardt and Tim Kirchmann are employees of AbbVie GmbH. Fränce Hardtstock and Zeki Kocaata are employees of Ingress-Health and have no conflict of interest to declare. Thomas Wilke, who is the managing director of IPAM e.V., has worked as a consultant for Boehringer Ingelheim Pharma, Bayer Health Care, GSK, Novartis, Sanofi-Aventis, Bristol Myers Squibb, Pfizer and other pharmaceutical companies. Ulf Maywald works for one of the insurance funds that provided the study data (AOK PLUS). Zaza Katsarava is a Director and Trustee of 'Lifting The Burden' and the 'European Headache Federation' and has supported the study as a scientific advisor. Otherwise, he does not declare a conflict of interest.

\section{Funding}

This study was financially supported by AbbVie GmbH.

\section{Authors contributions}

All authors ( $\mathrm{FH}, \mathrm{ZK}, \mathrm{TW}, \mathrm{ZK}, \mathrm{TK}, \mathrm{UM}, \mathrm{AE})$ were involved in the conceptualization and the design of the study and interpretation of the data. FH, ZK and TW analyzed the data and drafted the manuscript. All authors ( $\mathrm{FH}, \mathrm{ZK}, \mathrm{TW}, \mathrm{ZK}, \mathrm{TK}, \mathrm{UM}, \mathrm{AE})$ critically reviewed the article and made substantial contributions to the finalization of the manuscript, especially including the discussion section, and have given their final approval of the version to be submitted.

\section{Acknowledgements}

Non-applicable

\section{References}

1. 10.1186/s10194-018-0846-2

Steiner TJ, Stovner LJ, Vos T, Jensen R, Katsarava Z, "Migraine is first cause of disability in under 50s: will health politicians now take notice?," Journal of Headache and Pain, vol. 19, no. 1. SpringerVerlag Italia s.r.l., Dec. 01, 2018, doi: 10.1186/s10194-018-0846-2

2. $10.1186 / \mathrm{s} 10194-015-0516-6$

Gaul C, Diener HC, Danesch U, "Improvement of migraine symptoms with a proprietary supplement containing riboflavin, magnesium and Q10: a randomized, placebo-controlled, double-blind, multicenter trial," J. Headache Pain, vol. 16, no. 1, Dec. 2015, doi: 10.1186/s10194-015-0516-6 
3. $10.1177 / 204946371100500402$

Bahra A, “Primary Headache Disorders: Focus on Migraine,” Rev. Pain, vol. 5, no. 4, pp. 2-11, Dec. 2011, doi: 10.1177/204946371100500402

4. 10.1016/S1474-4422(10)70005-3

Goadsby PJ, Sprenger T, “Current practice and future directions in the prevention and acute management of migraine.," Lancet. Neurol., vol. 9, no. 3, pp. 285-98, Mar. 2010, doi: 10.1016/S14744422(10)70005-3

5. Puledda F, Shields K (2018) “Non-Pharmacological Approaches for Migraine. " Neurotherapeutics 15(2):336-345. doi:10.1007/s13311-018-0623-6

6. $10.1111 /$ head. 12857

Coeytaux RR, Befus D, "Role of Acupuncture in the Treatment or Prevention of Migraine, Tension-Type Headache, or Chronic Headache Disorders," Headache, vol. 56, no. 7. Blackwell Publishing Inc., pp. 1238-1240, Jul. 01, 2016, doi: 10.1111/head.12857

7. Vos T et al (Sep. 2017) Global, regional, and national incidence, prevalence, and years lived with disability for 328 diseases and injuries for 195 countries, 1990-2016: A systematic analysis for the Global Burden of Disease Study 2016. Lancet 390(10100):1211-1259. doi:10.1016/S01406736(17)32154-2

8. Katsarava Z, Mania M, Lampl C, Herberhold J, Steiner TJ, “Poor medical care for people with migraine in Europe - evidence from the Eurolight study," J Headache Pain, 19, 1, Dec. 2018, doi:10.1186/s10194-018-0839-1

9. Vo P, Fang J, Bilitou A, Laflamme AK, Gupta S (Sep. 2018) Patients' perspective on the burden of migraine in Europe: a cross-sectional analysis of survey data in France, Germany, Italy, Spain, and the United Kingdom. J Headache Pain 19(1):82. doi:10.1186/s10194-018-0907-6

10. Piccinni C et al., "A real-world study on unmet medical needs in triptan-treated migraine: Prevalence, preventive therapies and triptan use modification from a large Italian population along two years," J Headache Pain, 20, 1, Jun. 2019, doi:10.1186/s10194-019-1027-7

11. Wells RE, Bertisch SM, Buettner C, Phillips RS, McCarthy EP, “Complementary and alternative medicine use among adults with migraines/severe headaches.," Headache, vol. 51, no. 7, pp. 108797, doi: 10.1111/j.1526-4610.2011.01917.x

12. World Health Organization, "Introduction to Drug Utilization Research World Health Organization WHO International Working Group for Drug Statistics Methodology," World Heal Organ, 2003, doi:10.3389/fimmu.2017.00344

13. Verdienste ZD, “Verdienststrukturerhebung,” vol. 2017, no. 0, 2017

14. Steiner TJ, Antonaci F, Jensen R, Lainez MJA, Lanteri-Minet M, Valade D (Aug. 2011) Recommendations for headache service organisation and delivery in Europe. J Headache Pain 12(4):419-426. doi:10.1007/s10194-011-0320-x

15. $10.1186 / s 10194-018-0899-2$

Page 19/23 
Steiner TJ et al., "Aids to management of headache disorders in primary care (2nd edition): On behalf of the European Headache Federation and Lifting the Burden: The Global Campaign against Headache," J. Headache Pain, vol. 20, no. 1, May 2019, doi: 10.1186/s10194-018-0899-2

16. Diener HC, Gaul C, Kropp P (2018) Therapie der Migräneattacke und Prophylaxe der Migräne. Nervenheilkunde 37(10):689-715. doi:10.1055/s-0038-1673598

17. $10.1111 /$ papr.12520

Jacob L, Kostev K, "Prescription Patterns and the Cost of Migraine Treatments in German General and Neurological Practices," Pain Pract., vol. 17, no. 6, pp. 747-752, Jul. 2017, doi:

10.1111/papr. 12520

18. Katsarava Z, Steiner TJ, “Neglected headache: Ignorance, arrogance or insouciance?" Cephalalgia, 32, no. 14. 1019-10200ct. 2012, doi:10.1177/0333102412459478

19. $10.1177 / 0333102412454945$

Radtke A, Neuhauser $\mathrm{H}$, "Low rate of self-awareness and medical recognition of migraine in Germany," Cephalalgia, vol. 32, no. 14, pp. 1023-1030, Oct. 2012, doi: 10.1177/0333102412454945

20. Lucas C, Géraud G, Valade D, Chautard MH, Lantéri-Minet M, "Recognition and therapeutic management of migraine in 2004, in France: Results of FRAMIG 3, a French nationwide populationbased survey," Headache, 46, no. 5. 715-725May 2006, doi:10.1111/j.1526-4610.2006.00430.x

21. Radtke A, Neuhauser H (Jan. 2009) Prevalence and burden of headache and migraine in Germany. Headache 49(1):79-89. doi:10.1111/j.1526-4610.2008.01263.x

22. 10.1111/j.1468-2982.2009.01874.x

Cevoli $S$ et al., "Underdiagnosis and undertreatment of migraine in Italy: A survey of patients attending for the first time 10 headache centres," Cephalalgia, vol. 29, no. 12, pp. 1285-1293, Dec. 2009, doi: 10.1111/j.1468-2982.2009.01874.x

23. $10.1111 /$ ene. 14098

Viana $\mathrm{M}$ et al., "Poor patient awareness and frequent misdiagnosis of migraine: findings from a large transcontinental cohort," Eur. J. Neurol., vol. 27, no. 3, pp. 536-541, Mar. 2020, doi:

10.1111/ene. 14098

24. $10.3399 /$ bjgp14X681325

Bösner S, Hartel S, Diederich J, Baum E, "Diagnosing headache in primary care: A qualitative study of GPs' approaches," Br. J. Gen. Pract., vol. 64, no. 626, pp. e532-e537, Sep. 2014, doi: 10.3399/bjgp14X681325

25. $10.1111 /$ head.12055

Blumenfeld AM et al., "Patterns of use and reasons for discontinuation of prophylactic medications for episodic migraine and chronic migraine: Results from the second international burden of migraine study (IBMS-II)," Headache, vol. 53, no. 4, pp. 644-655, Apr. 2013, doi: 10.1111/head.12055

26. $10.1177 / 0333102416678382$

Hepp Z et al., "Persistence and switching patterns of oral migraine prophylactic medications among patients with chronic migraine: A retrospective claims analysis," Cephalalgia, vol. 37, no. 5, pp. 470- 
485, Apr. 2017, doi: 10.1177/0333102416678382

27. Linde $\mathrm{M}$ et al (May 2012) The cost of headache disorders in Europe: The Eurolight project. Eur $\mathrm{J}$ Neurol 19(5):703-711. doi:10.1111/j.1468-1331.2011.03612.x

28. Hawkins $K$, Wang S, Rupnow M, "Direct cost burden among insured US employees with migraine," Headache, vol. 48, no. 4, pp. 553-563, Apr. 2008

29. Bloudek LM et al (Jul. 2012) Cost of healthcare for patients with migraine in five European countries: results from the International Burden of Migraine Study (IBMS). " J Headache Pain 13(5):361-378

30. The World Health Organization, "Atlas of headache disorders and resources in the world 2011," World Heal. Organ., p. 72, 2011

Figures

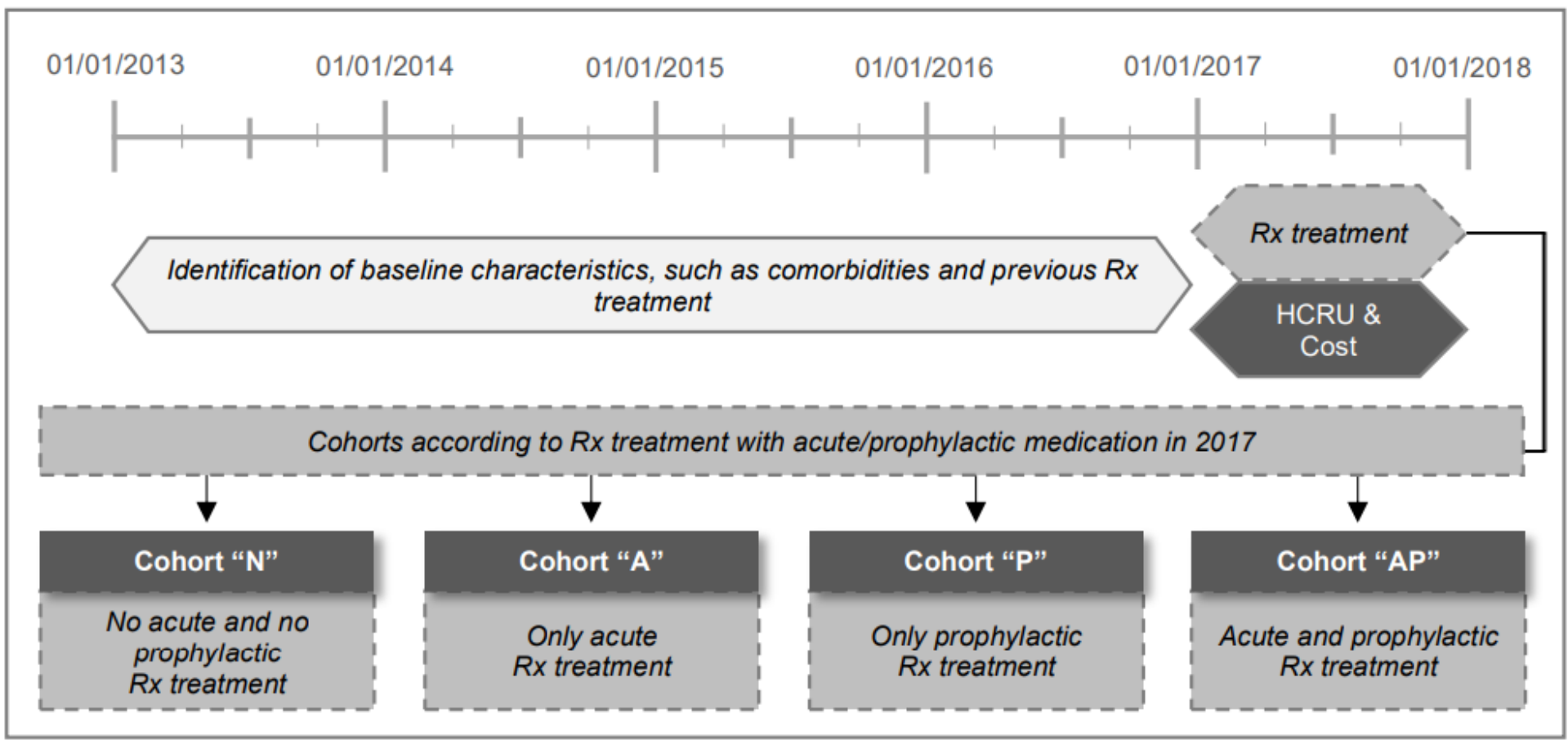

\section{Figure 1}

Study design scheme of HCRU/cost analysis in 2017 


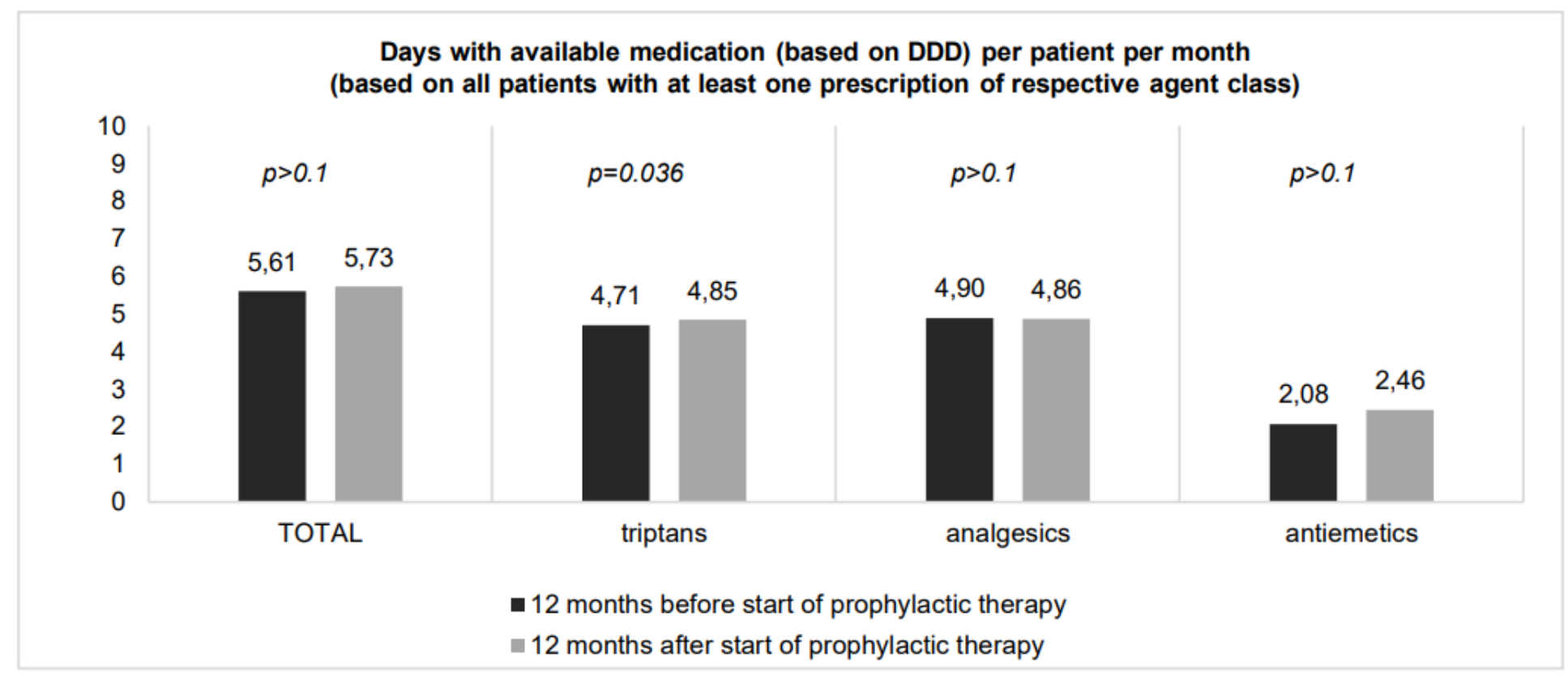

Figure 2

Acute medications before and after start of prophylactic $1 \mathrm{~L}$ treatment Note: Ergot alkaloids are not reported because of the low number of patients with prescriptions.

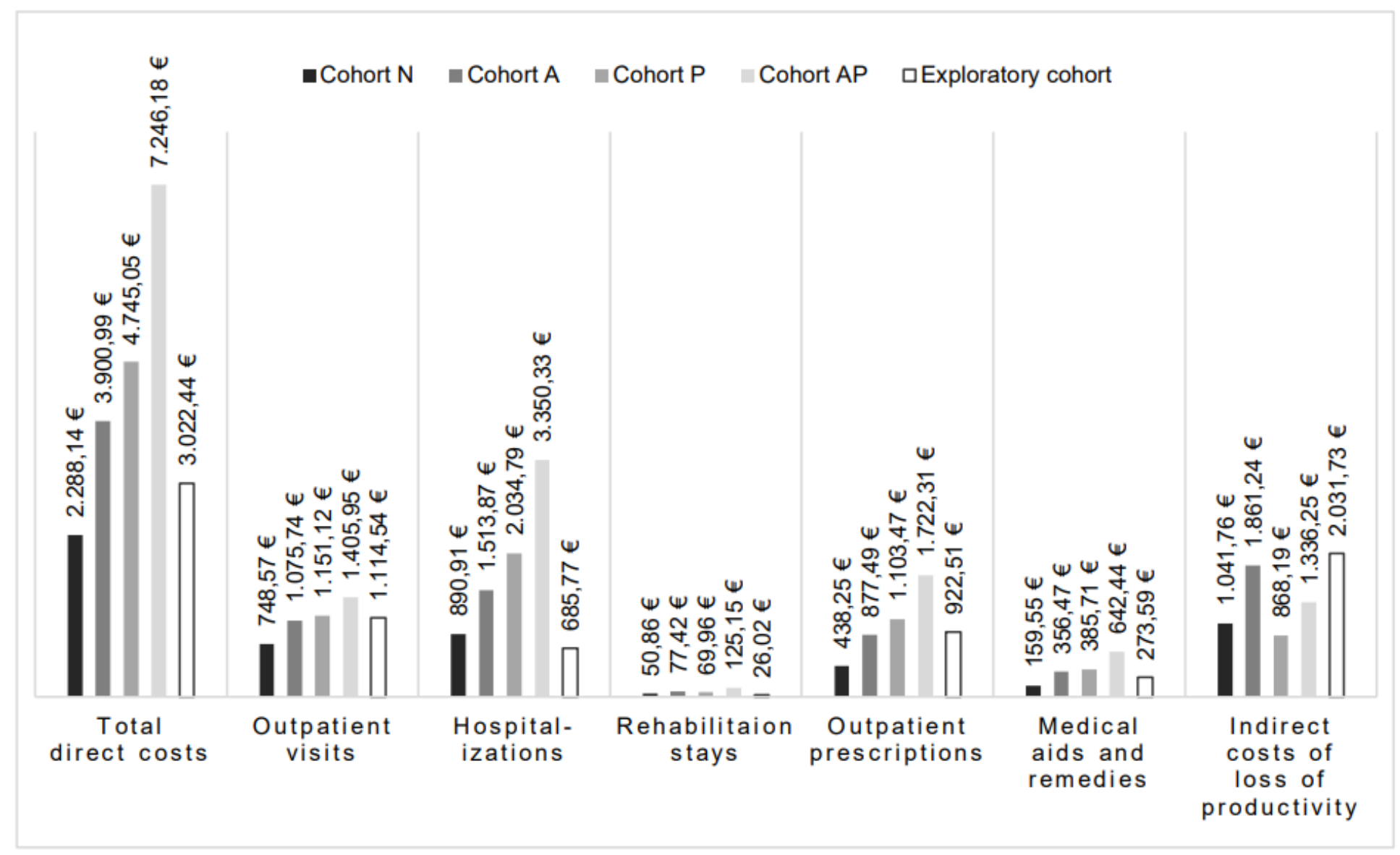

Figure 3 
Costs in 2017 per patient-year in $€$

Page 23/23 